\title{
Peptidyl arginine deiminase type IV (PADI4)
} haplotypes interact with shared epitope regardless of anti-cyclic citrullinated peptide antibody or erosive joint status in rheumatoid arthritis: a case control study

So-Young Bang ${ }^{1}$, Tae-Un Han², Chan-Bum Choi', Yoon-Kyoung Sung ${ }^{1}$, Sang-Cheol Bae*1 and Changwon Kang ${ }^{* 2}$

\begin{abstract}
Introduction: Anti-cyclic citrullinated peptide autoantibodies (anti-CCP) are the most specific serologic marker for rheumatoid arthritis (RA). Genetic polymorphisms in a citrullinating (or deiminating) enzyme, peptidyl arginine deiminase type IV (PADI4) have been reproducibly associated with RA susceptibility in several populations. We investigated whether PAD/4 polymorphisms contribute to anti-CCP-negative as well as -positive RA, whether they influence disease severity (erosive joint status), and whether they interact with two major risk factors for RA, Human Leukocyte Antigen-DRB1 (HLA-DRB1) shared epitope (SE) alleles and smoking, depending on anti-CCP and erosive joint status.

Methods: All 2,317 unrelated Korean subjects including 1,313 patients with RA and 1,004 unaffected controls were genotyped for three nonsynonymous (padi4_89, padi4_90, and padi4_92) and one synonymous (padi4_104) singlenucleotide polymorphisms (SNPs) in PAD/4 and for HLA-DRB1 by direct DNA sequence analysis. Odds ratios (OR) were calculated by multivariate logistic regression. Interaction was evaluated by attributable proportions (AP), with 95\% confidence intervals $(\mathrm{Cl})$.
\end{abstract}

Results: A functional haplotype of the three fully correlated nonsynonymous SNPs in PAD/4 was significantly associated with susceptibility to not only anti-CCP-positive (adjusted OR 1.73, 95\% Cl 1.34 to 2.23) but also -negative RA (adjusted OR $1.75,95 \% \mathrm{Cl} 1.15$ to 2.68). A strong association with both non-erosive (adjusted OR 1.62, 95\% Cl 1.29 to 2.05) and erosive RA (adjusted OR 1.62, 95\% Cl 1.14 to 2.31) was observed for PAD/4 haplotype. Gene-gene interactions between the homozygous RA-risk PAD/4 haplotype and SE alleles were significant in both anti-CCP-positive (AP $0.45,95 \% \mathrm{Cl} 0.20$ to 0.71 ) and -negative RA (AP $0.61,95 \% \mathrm{Cl} 0.29$ to 0.92 ). Theses interactions were also observed for both non-erosive (AP $0.48,95 \% \mathrm{Cl} 0.25$ to 0.72 ) and erosive RA (AP $0.46,95 \% \mathrm{Cl} 0.14$ to 0.78 ). In contrast, no interaction was observed between smoking and PAD/4 polymorphisms.

Conclusions: A haplotype of nonsynonymous SNPs in PAD/4 contributes to development of RA regardless of anti-CCP or erosive joint status. The homozygous PAD/4 haplotype contribution is affected by gene-gene interactions with HLADRB1 SE alleles.

\footnotetext{
* Correspondence: scbae@hanyang.ac.kr, ckang@kaist.ac.kr

1 Department of Rheumatology, Hanyang University Hospital for Rheumatic Diseases, 17 Hangdang-dong Seongdong-gu, Seoul 133-792, South Korea 2 Department of Biological Sciences, Korea Advanced Institute of Science and Technology, 335 Gwahangno Yuseong-gu, Daejeon 305-701, South Korea Full list of author information is available at the end of the article
}

() 2010 Bang et al.; licensee BioMed Central Ltd. This is an open access article distributed under the terms of the Creative Commons B. W 1 Central Attribution License (http://creativecommons.org/licenses/by/2.0), which permits unrestricted use, distribution, and reproduction in any medium, provided the original work is properly cited. 


\section{Introduction}

Rheumatoid arthritis (RA) is a chronic inflammatory disease with a complex etiology that involves both genetic and environmental contributions; the pathogenesis of RA is still not fully understood. The genetic component of RA pathogenesis may account for up to $60 \%$, and the Human Leukocyte Antigen (HLA) region in particular has shown the strongest genetic association with RA $[1,2]$. The Human Leukocyte Antigen-DRB1 (HLA-DRB1) shared epitope (SE) alleles are the most potent genetic risk factor for RA [2-5]. However, the effect of HLA polymorphisms accounts for only one-third of the overall genetic contribution observed. The peptidyl arginine deiminase type IV gene (PADI4) has been shown in several studies to be an additional RA susceptibility gene in Asians and in some Caucasian populations [6-11]. However, in several other Caucasian populations, no association has been found between PADI4 and RA [12-15].

Anti-cyclic citrullinated peptide autoantibodies (antiCCP) are highly specific for RA [16-19], and the enzyme PADI4 deiminates certain arginine residues to citrullines in some proteins. The anti-CCP were detected more frequently in RA patients who were homozygous for an RAsusceptible haplotype of PADI4, and PADI4 messenger RNA (mRNA) of the susceptible haplotype was more stable than mRNA without it in a Japanese study [6]. We have previously demonstrated that increased serum levels of anti-CCP are associated with the RA-risk PADI4 haplotype in patients within 34 months of disease duration [20]. Accordingly, PADI4 may play a role in the citrullinating pathway of anti-CCP-positive RA pathogenesis. However, it has never been investigated whether the RArisk haplotype of PADI4 contributes to the development of anti-CCP-negative RA as well.

Recently, it was reported that the association of PADI4 SNP with RA was restricted to patients with erosive disease (Steinbrocker score >II) in Caucasians [21]. However, their results were based on retrospective case-only analysis in a small sample size study.

Smoking is a major environmental risk factor for RA. It has been shown that smoking may trigger the RA immune reaction to citrullinated proteins and interact with SE alleles in development of RA [22-25]. Gene-environment interactions between SE alleles and smoking have been demonstrated in the development of antiCCP-positive RA only [24,26-28]. However, we recently observed that SE alleles and smoking are associated with RA susceptibility in anti-CCP-positive as well as -negative RA [29]. A possible interaction between single SNP of PADI4 and smoking has been previously reported [30], but sample size examined was too small to fully clarify the gene-environment interactions. Therefore, this needs to be confirmed for other populations in large scale studies.
We studied a large case-control study to scrutinize the effects of PADI4 on joint destruction as an indicator of RA severity and synergic effects of PADI4 and major risk factors (SE alleles, smoking). First, we investigated whether PADI4 polymorphisms contribute differently to two subsets of RA categorized according to the presence and absence of anti-CCP or erosive joint state, respectively. Second, we assessed whether PADI4 polymorphisms interact with the $H L A-D R B 1$ SE alleles in antiCCP-positive/-negative RA as well as in non-erosive/erosive RA. Third, we investigated whether a gene-environment interaction occurs between PADI4 polymorphisms and smoking in a Korean population. Our findings provide insight into the pathogenic role of PADI4 in developing RA.

\section{Materials and methods Patients and controls}

A total of 2,317 unrelated Korean subjects including 1,313 RA patients and 1,004 healthy controls, who were successfully genotyped for four exonic PADI4 SNPs and for $H L A-D R B 1$, were included in this study among those recruited at Hanyang University Hospital for Rheumatic Diseases. All patients with RA met the American College of Rheumatology 1987 classification criteria [31]. Information about smoking status was obtained from 1,288 (98.1\%) patients with RA and 991 (98.7\%) controls in Korea. Information about direct smoking status was obtained using the same questionnaire given directly to the cases and controls by trained interviewers. Eversmokers were defined as those individuals who had ever smoked cigarettes before the onset of RA. All patients with RA were classified into non-erosive (Steinbrocker stage I) and erosive (Steinbrocker stages II-IV) as a marker of RA severity at the time of enrollment [32]. Stage I RA was defined as the absence of destructive changes on radiographs, stage II RA as radiographic evidence of osteoporosis, with or without slight subchondral bone destruction or slight cartilage destruction, stage III RA as radiographic evidence of cartilage and bone destruction, subluxation, or ulnar deviation, and stage IV RA as fibrous or bony ankylosis.

The baseline characteristics of the RA patient and control subjects are shown in Table 1 . The study was approved by the Institutional Review Board of Hanyang University Medical Center. Informed consent was obtained from all patients with RA and controls.

\section{Genotyping of PADI4 SNPs}

Genomic DNA was extracted from peripheral blood mononuclear cells using the method of Miller et al. [33]. All RA patients and controls were genotyped for three nonsynonymous SNPs (padi4_89 (rs11203366), padi4_90 (rs11203367), and padi4_92 (rs874881)) and one synony- 
Table 1: Basic characteristics of patients with RA and control subjects*

\begin{tabular}{|c|c|c|c|c|}
\hline & $\begin{array}{c}\text { Controls } \\
(n=1,004)\end{array}$ & $\begin{array}{c}\text { RA cases } \\
(n=1,313)\end{array}$ & $\begin{array}{c}\text { anti-CCP-positive RA } \\
(\mathbf{n}=\mathbf{8 2 2})\end{array}$ & $\begin{array}{c}\text { anti-CCP-negative RA } \\
(n=145)\end{array}$ \\
\hline Female, No. (\%) & $864(86.1)$ & $1,170(89.1)$ & $734(89.3)$ & $128(88.3)$ \\
\hline Age (mean \pm SD years) & $36.7 \pm 12.5$ & $51.8 \pm 12.2$ & $51.7 \pm 11.8$ & $50.5 \pm 11.3$ \\
\hline Onset age (mean \pm SD years) & - & $40.6 \pm 12.4$ & $40.5 \pm 12.1$ & $38.5 \pm 11.9$ \\
\hline Ever-smokers, No. (\%) & $134(13.5)$ & $197(15.3)$ & $119(14.6)$ & $26(17.9)$ \\
\hline Erosive disease (\%) & - & $1,071(81.6)$ & $682(83.0)$ & $113(77.9)$ \\
\hline
\end{tabular}

* Except where indicated otherwise, values are the number (\%). Among patients with rheumatoid arthritis (RA), 1,288 were evaluated for ever smokers, and 967 were evaluated for anti--cyclic citrullinated peptide antibodies (anti-CCP). Among control subjects, 991 were evaluated for ever smokers. Out of these subjects, 311 cases and 392 controls had been included in a previous study by Cha et al. [20].

mous SNP (padi4_104 (rs1748033)) in PADI4. Genotyping was performed using the MassARRAY system (Sequenom, San Diego, CA, USA) as described previously $[8,20]$ with approval from the Institutional Review Board of Korea Advanced Institute of Science and Technology. The genotype distributions of cases and controls were found to be in Hardy-Weinberg equilibrium.

\section{Genotyping of HLA-DRB1}

Allele-level genotypes of the $H L A-D R B 1$ gene were obtained by conventional polymerase chain reaction sequence based typing method, as described previously [34]. Briefly, the polymorphic exon 2 of the DRB1 gene was amplified using group-specific primer sets, and was sequenced by automated cycle sequencing based on dye terminator chemistry using an ABI3100 Genetic Analyzer (Life Technologies, Carlsbad, CA, USA). The SE alleles were "0101, "0102, "0401, "0404, "0405, "0408, "0410, "1001, "1402, and *1406.

\section{Measurement of anti-CCP}

The serum concentration of anti-CCP was measured for 967 RA patients (73.6\% of the total 1,313 patients) using the ImmuLisa CCP ELISA test (IMMCO Diagnostics, Buffalo, NY, USA). Among them, 822 patients were positive $(85.0 \%)$ with serum concentration levels of 25 units/ $\mathrm{ml}$ or higher.

\section{Statistical analysis}

The odds ratios (OR) and 95\% confidence intervals (CI) of developing RA depending on anti-CCP or erosive joint status were calculated using multivariate logistic regression and adjusted for age and sex. The attributable proportions (AP) with 95\% CI were also calculated to measure the gene-gene and gene-environment interactions according to anti-CCP and erosive joint status $[28,35,36]$. $P$-values less than 0.05 were considered significant. All statistical analyses were performed using SPSS software version 12.0 (SPSS Inc., Chicago, IL, USA). Inter-SNP linkage disequilibrium (LD) $\mathrm{r}^{2}$ values among
SNPs in PADI4 were calculated using the Haploview 4.0 program, and haplotypes were reconstructed using the Bayesian algorithm-based program Phase, version 2.1 [37]. Adjustment was also made for confounding factor by residential area. But, residential area had a negligible influence on our results and was not retained in final analyses.

\section{Results}

Confirmed association of PADI4 with RA susceptibility

In this Korean population of 1,313 patients with RA and 1,004 healthy controls (Table 1), the minor alleles in four exonic SNPs of PADI4 were each shown to be associated with increased susceptibility to RA confirming previous association results obtained using a subset of this study population $[8,20]$. The three nonsynonymous SNPs (padi4_89, padi4_90 and padi4_92) in PADI4 were fully correlated $\left(\mathrm{r}^{2}=1.00\right)$ with each other in controls and RA patients, and constitute only two common haplotypes, ACC and GTG (with letters representing the nucleotides found at padi4_89, padi4_90, and padi4_92, respectively) in all subjects except only for three. Extremely rare haplotypes ACG $(\mathrm{n}=4)$, and GCC $(\mathrm{n}=1)$ were excluded from analysis. Carriage of padi4_89 (OR 1.41, 95\% CI 1.26 to 1.59), padi4_90 (OR 1.41, 95\% CI 1.26 to 1.59 ), and padi4_92 (OR 1.42, 95\% CI 1.26 to 1.60) were associated with susceptibility to RA. The minor haplotype GTG carrying the minor RA-risk alleles had 1.42-fold increased odds of having RA than the major haplotype ACC carrying the major non-risk alleles, and GTG carriers had 1.64fold increased odds versus the non-carriers having ACC/ ACC. The fourth, synonymous SNP (padi4_104) in PADI4 was also associated with RA susceptibility (OR $1.33,95 \%$ CI 1.18 to 1.50 ), but this allelic association was not statistically independent from the above haplotype association because this SNP was very highly correlated $\left(\mathrm{r}^{2}=0.78\right.$ approximately 0.79$)$ with the nonsynonymous SNPs. In fact, the synonymous SNP association vanished $(P=0.31)$ when adjusted for the nonsynonymous SNPs. 
Therefore, the PADI4 association with RA was assessed only with the nonsynonymous-SNP haplotypes in the subsequent analyses.

Additionally, RA susceptibility associations of $H L A$ $D R B 1$ SE alleles and smoking were confirmed in this population [29]. Although ORs for GTG haplotype and SE alleles were higher in this study with adjustment for smoking than in a previous study without such adjustment [8], the enrolled study population was suitable for analyzing the effects of RA-risk PADI4 haplotype, SE alleles, and smoking in stratification with anti-CCP positivity and for assessing their interactions.

\section{Association of PADI4 with RA according to anti-CCP or erosive joint status}

PADI4 haplotype GTG carriers had 1.73-fold and 1.75fold increased odds of anti-CCP-positive and -negative RA, respectively, compared with the non-carriers having only ACC, after adjustment for age, sex, SE alleles, and smoking (Table 2). HLA-DRB1 SE carriers had 5.18-fold and 2.31-fold increased odds of anti-CCP-positive and negative RA, respectively, versus the non-carriers. In addition, ever-smokers had 2.17-fold and 2.77-fold increased odds of anti-CCP-positive and -negative RA, respectively, versus the non-smokers. Accordingly, all three RA-risk factors, PADI4 GTG carriage, HLA-DRB1 $\mathrm{SE}$ alleles and smoking were each associated with susceptibility to not only anti-CCP-positive but also -negative RA.

In 1,313 patients with RA, 81.6\% (Steinbrocker stages II-IV) had erosive joint disease (stage I, 18.4\%; stage II, 34.3\%; stage III 31.3\%; stage IV 15.9\%). PADI4 haplotype GTG carriers had 1.62-fold and 1.62-fold increased odds of erosive and non-erosive RA, respectively (Table 3 ). HLA-DRB1 SE carriers also had 4.45-fold and 4.16-fold increased odds of erosive and non-erosive RA. In addition, ever-smokers had 2.01-fold and 3.83-fold increased odds of erosive and non-erosive RA. Accordingly, all three RA-risk factors, PADI4 GTG carriage, HLA-DRB1 $\mathrm{SE}$ alleles and smoking were each associated with susceptibility regardless of erosive joint status in multivariate analyses.

\section{Gene-gene interactions between PADI4 haplotype and HLA-DRB1 SE alleles}

The strength of the interactions was measured by AP of the RA-developing risk (Table 4). In anti-CCP-positive/ anti-CCP-negative RA, individuals carrying GTG and SE had a higher risk of developing RA than those carrying neither GTG nor SE. The risk of anti-CCP-positive RA (OR 11.63, 95\% CI 7.73 to 17.51 ) associated with the presence of GTG and SE was much higher than that of antiCCP-negative RA (OR 4.10, 95\% CI 2.23 to 7.53). However, there were no statistically significant interactions between GTG carriage and SE carriage in anti-CCP-positive RA or anti-CCP-negative RA (Table 4).

In addition, we analyzed the interaction between PADI4 diplotypes (rather than haplotype) and SE carriage. SE carriers homozygous for GTG haplotype were strongly associated with high risk of both anti-CCP-positive RA (OR 19.45, 95\% CI 11.32 to 33.42) and anti-CCPnegative RA (OR 9.59, 95\% CI 4.39 to 20.98) compared with SE non-carriers homozygous for the non-risk haplotype ACC. The GTG homozygote interacted with SE alleles to increase the risk of developing anti-CCP-posi-

Table 2: Association of PADI4 haplotypes, HLA-DRB1 SE alleles and smoking with susceptibility to anti-CCP-positive and negative $\mathbf{R A} *$

\begin{tabular}{|c|c|c|c|c|c|c|c|}
\hline \multirow[b]{2}{*}{ Subgroup } & \multirow[t]{2}{*}{ Controls, No } & \multicolumn{2}{|c|}{ All RA cases } & \multicolumn{2}{|c|}{ anti-CCP-positive RA } & \multicolumn{2}{|c|}{ anti-CCP-negative RA } \\
\hline & & No. & OR $(95 \% \mathrm{CI})$ & No. & OR $(95 \% \mathrm{CI})$ & No. & OR $(95 \% \mathrm{CI})$ \\
\hline GTG-negative† & 378 & 366 & 1 & 218 & 1 & 39 & 1 \\
\hline GTG-positive & 625 & 945 & 1.64 (1.31 to 2.05$)$ & 602 & 1.73 (1.34 to 2.23$)$ & 106 & 1.75 (1.15 to 2.68$)$ \\
\hline SE-negative & 644 & 429 & 1 & 226 & 1 & 71 & 1 \\
\hline SE-positive & 359 & 882 & 4.31 (3.49 to 5.32$)$ & 594 & $5.18(4.54$ to 7.45$)$ & 74 & $2.31(1.57$ to 3.41$)$ \\
\hline Non-smoking & 856 & 1,089 & 1 & 692 & 1 & 119 & 1 \\
\hline Smoking & 134 & 197 & $2.28(1.47$ to 3.52$)$ & 119 & $2.17(1.29$ to 3.63$)$ & 26 & $2.77(1.30$ to 5.90$)$ \\
\hline
\end{tabular}

* Values are the number of subjects. OR and $95 \% \mathrm{Cl}$ for GTG carriage versus non-carriage were adjusted for age, sex, SE alleles and smoking. $\mathrm{OR}$ and $95 \% \mathrm{Cl}$ for SE carriage versus non-carriage were adjusted for age, sex, GTG carriage and smoking. OR and $95 \% \mathrm{Cl}$ for smoking versus non-smoking were adjusted for age, sex, GTG carriage and SE alleles. RA, rheumatoid arthritis; anti-CCP, anti-cyclic citrullinated peptide autoantibody; $\mathrm{OR}$, odds ratios; $\mathrm{Cl}$, confidence intervals.

† The letters in PADI4 haplotypes represent nucleotides in padi4_89, padi4_90, and padi4_92 SNPs, respectively. Extremely rare haplotypes ACG $(n=4)$, and GCC $(n=1)$ were excluded from analysis. Three subjects (two RA patients and one control) who carried ACC and a rare haplotype were excluded from the analysis and hence the GTG-negative subjects carried only ACC/ACC. 
Table 3: Association of PADI4 haplotypes, HLA-DRB1 SE alleles and smoking with susceptibility to erosive and non-erosive RA*

\begin{tabular}{|c|c|c|c|c|c|c|c|}
\hline \multirow[b]{2}{*}{ Subgroup } & \multirow[t]{2}{*}{ Controls, No } & \multicolumn{2}{|c|}{ All RA cases } & \multicolumn{2}{|r|}{ Erosive RA } & \multicolumn{2}{|c|}{ Non-erosive RA } \\
\hline & & No. & OR $(95 \% \mathrm{Cl})$ & No. & OR $(95 \% \mathrm{Cl})$ & No. & OR $(95 \% \mathrm{Cl})$ \\
\hline GTG-negative $†$ & 378 & 366 & 1 & 299 & 1 & 67 & 1 \\
\hline GTG-positive & 625 & 945 & 1.64 (1.31 to 2.05 ) & 771 & 1.62 (1.29 to 2.05 ) & 174 & 1.62 (1.14 to 2.31$)$ \\
\hline SE-negative & 644 & 429 & 1 & 346 & 1 & 83 & 1 \\
\hline SE-positive & 359 & 882 & 4.31 (3.49 to 5.32 ) & 724 & 4.45 (3.55 to 5.57 ) & 158 & 4.16 (2.97 to 5.83 ) \\
\hline Non-smoking & 856 & 1,089 & 1 & 904 & 1 & 185 & 1 \\
\hline Smoking & 134 & 197 & 2.28 (1.47 to 3.52 ) & 146 & 2.01 (1.25 to 3.25$)$ & 51 & 3.83 (2.02 to 7.27 ) \\
\hline
\end{tabular}

tive RA (AP 0.45 , 95\% CI 0.20 to 0.71 ) as well as antiCCP-negative RA (AP 0.61, 95\% CI 0.29 to 0.92 ).

As shown in Table 5, the combination of homozygous PADI4 haplotype and HLA-DRB1 SE alleles significantly increased the risk in patients with RA (for non-erosive RA (OR 14.47, 95\% CI 7.11 to 29.45); for erosive RA (OR $12.98,95 \%$ CI 7.97 to 21.14$)$ ). The AP (95\% CI) due to gene-gene interaction between homozygous PADI4 haplotype and SE alleles was $0.48(0.25$ to 0.72$)$ in erosive disease and $0.46(0.14$ to 0.78$)$ in non-erosive disease (Table $5)$.

We also investigated interaction between homozygous PADI4 haplotype and SE alleles in non-erosive and erosive RA according to anti-CCP status. The AP was 0.47

Table 4: Interaction between PADI4 haplotypes and SE alleles in susceptibility to anti-CCP-positive and -negative RA*

\begin{tabular}{|c|c|c|c|c|c|c|c|}
\hline \multirow[b]{2}{*}{ Subgroup } & \multirow[t]{2}{*}{ Controls, No } & \multicolumn{2}{|r|}{ All RA cases } & \multicolumn{2}{|c|}{ anti-CCP-positive RA } & \multicolumn{2}{|c|}{ anti-CCP-negative RA } \\
\hline & & No. & OR $(95 \% \mathrm{CI})$ & No. & OR $(95 \% \mathrm{Cl})$ & No. & OR $(95 \% \mathrm{Cl})$ \\
\hline GTG and SE carriage & 1,003 & 1,311 & & 820 & & 145 & \\
\hline GTG-negative/SE-negative & 245 & 109 & 1 & 50 & 1 & 18 & 1 \\
\hline GTG-positive/SE-negative & 399 & 320 & 1.89 (1.37 to 2.61$)$ & 176 & 2.32 (1.54 to 3.49$)$ & 53 & $1.80(0.99$ to 3.25$) 9$ \\
\hline GTG-positive/SE-positive† & 226 & 625 & $7.46(5.38$ to 10.36$)$ & 426 & 11.63 (7.73 to 17.51$)$ & 53 & $4.10(2.23$ to 7.53$)$ \\
\hline Diplotype and SE carriage & 1,003 & 1,311 & & 820 & & 145 & \\
\hline ACC/ACC/SE-negative & 245 & 109 & 1 & 50 & 1 & 18 & 1 \\
\hline ACC/GTG/SE-negative & 290 & 217 & 1.72 (1.22 to 2.42$)$ & 122 & 2.14 (1.39 to 3.30$)$ & 33 & $1.52(0.81$ to 2.88$) 9$ \\
\hline GTG/GTG/SE-negative & 109 & 103 & 2.39 (1.56 to 3.66$)$ & 54 & 2.85 (1.68 to 4.85$)$ & 20 & $2.58(1.24$ to 5.37$)$ \\
\hline ACC/ACC/SE-positive & 133 & 257 & 5.19 (3.58 to 7.51$)$ & 168 & $8.24(5.25$ to 12.92$)$ & 21 & 2.41 (1.18 to 4.92$)$ \\
\hline ACC/GTG/SE-positive & 179 & 428 & 6.23 (4.42 to 8.77$)$ & 298 & $9.87(6.47$ to 15.06$)$ & 31 & $2.90(1.50$ to 5.60$)$ \\
\hline GTG/GTG/SE-positive‡ & 47 & 197 & 12.74 (8.03 to 20.23$)$ & 128 & 19.45 (11.32 to 33.42$)$ & 22 & 9.59 (4.39 to 20.98$)$ \\
\hline
\end{tabular}

* OR and $95 \% \mathrm{Cl}$ were adjusted for age, sex, and smoking. RA, rheumatoid arthritis; anti-CCP, anti-cyclic citrullinated peptide autoantibody; OR, odds ratios; $\mathrm{Cl}$, confidence intervals.

† The attributable proportion $(95 \% \mathrm{Cl})$ due to interaction was $0.16(-0.10$ to 0.42$)$ in anti-CCP-positive RA and $0.19(-0.26$ to 0.63$)$ in anti-CCPnegative RA.

₹ The attributable proportion $(95 \% \mathrm{Cl})$ due to interaction was 0.45 ( 0.20 to 0.71$)$ in anti-CCP-positive RA and $0.61(0.29$ to 0.92$)$ in anti-CCPnegative RA.

१Association was not significant $(P=0.05$ and $P=0.20$, respectively). 
Table 5: Interaction between PADI4 haplotypes and SE alleles in susceptibility to erosive and non-erosive RA *

\begin{tabular}{|c|c|c|c|c|c|c|c|}
\hline \multirow[b]{2}{*}{ Subgroup } & \multirow[t]{2}{*}{ Controls, No } & \multicolumn{2}{|r|}{ All RA cases } & \multicolumn{2}{|r|}{ Erosive RA } & \multicolumn{2}{|r|}{ Non-erosive RA } \\
\hline & & No. & OR $(95 \% \mathrm{CI})$ & No. & OR (95\% Cl) & No. & OR $(95 \% \mathrm{CI})$ \\
\hline GTG and SE carriage & 1,003 & 1,311 & & 1,070 & & 241 & \\
\hline GTG-negative/SE-negative & 245 & 109 & 1 & 89 & 1 & 20 & 1 \\
\hline GTG-negative/SE-positive & 133 & 257 & 5.17 (3.57 to 7.48$)$ & 210 & 5.05 (3.41 to 7.47 ) & 47 & 5.70 (3.04 to 10.67$)$ \\
\hline GTG-positive/SE-negative & 399 & 320 & 1.89 (1.37 to 2.61$)$ & 257 & 1.80 (1.27 to 2.54$)$ & 63 & 2.11 (1.19 to 3.75$)$ \\
\hline GTG-positive/SE-positive & 226 & 625 & 7.46 (5.38 to 10.36$)$ & 514 & 7.52 (5.31 to 10.65$)$ & 111 & 7.73 (4.39 to 13.61$)$ \\
\hline Diplotype and SE carriage & 1,003 & 1,311 & & 1,070 & & 241 & \\
\hline ACC/ACC/SE-negative & 245 & 109 & 1 & 89 & 1 & 20 & 1 \\
\hline ACC/GTG/SE-negative & 290 & 217 & 1.72 (1.22 to 2.42$)$ & 177 & 1.65 (1.14 to 2.38$)$ & 40 & 1.85 (1.01 to 3.41$)$ \\
\hline GTG/GTG/SE-negative & 109 & 103 & 2.39 (1.56 to 3.66$)$ & 80 & 2.22 (1.41 to 3.50$)$ & 23 & 2.87 (1.40 to 5.86$)$ \\
\hline ACC/ACC/SE-positive & 133 & 257 & 5.19 (3.58 to 7.51$)$ & 210 & 5.07 (3.42 to 7.51$)$ & 47 & 5.71 (3.05 to 10.70$)$ \\
\hline ACC/GTG/SE-positive & 179 & 428 & 6.23 (4.42 to 8.77$)$ & 357 & 6.29 (4.37 to 9.03$)$ & 71 & 6.16 (3.41 to 11.11 \\
\hline GTG/GTG/SE-positiveł & 47 & 197 & 12.74 (8.03 to 20.23 ) & 157 & 12.98 (7.97 to 21.14$)$ & 40 & 14.47 (7.11 to 29.45 ) \\
\hline
\end{tabular}

* OR and $95 \% \mathrm{Cl}$ were adjusted for age, sex, and smoking. Erosive RA cases were classified as Steinbrocker scores II-IV. RA, rheumatoid arthritis; $\mathrm{OR}$, odds ratios; $\mathrm{Cl}$, confidence intervals.

† The attributable proportion $(95 \% \mathrm{Cl})$ due to interaction was 0.19 ( -0.06 to 0.43$)$ in erosive RA and $0.11(-0.27$ to 0.48$)$ in non-erosive RA.

₹ The attributable proportion $(95 \% \mathrm{Cl})$ due to interaction was 0.48 ( 0.25 to 0.72$)$ in erosive RA and $0.46(0.14$ to 0.78$)$ in non-erosive RA.

$(0.22$ to 0.73$)$ in erosive disease and $0.52(0.16$ to 0.87$)$ in non-erosive disease among anti-CCP-positive RA. The attributable proportion was $0.53(0.11$ to 0.95$)$ in erosive disease and 0.69 (0.32 to 1.06) in non-erosive disease among anti-CCP-negative RA, indicating that these interactions were statistically significant.

\section{No gene-environment interactions between PADI4 and smoking}

The combination of GTG carriage and smoking significantly increased the risk in patients with RA (for antiCCP-positive (OR 3.61, 95\% CI 1.98 to 6.57); for antiCCP-negative RA (OR 4.59, 95\% CI 1.91 to 11.04) (Supplementary table $\mathrm{S} 1$ in Additional file 1). The combination of the homozygous PADI4 haplotype and smoking significantly increased the risk in patients with RA (for anti-CCP-positive (OR 5.23, 95\% CI 2.30 to 11.87); for anti-CCP-negative RA (OR 9.20, 95\% CI 3.07 to 27.54).

However, no significant interactions were found between the GTG carriage and smoking for either antiCCP-positive (AP 0.10, 95\% CI -0.43 to 0.63 ) or antiCCP-negative RA (AP -0.17, 95\% CI -1.21 to 0.88) (Supplementary table S1 in Additional file 1). We also did not find any statistically significant interaction between the homozygous PADI4 haplotype and smoking in anti-CCPpositive RA (AP 0.23 , 95\% CI -0.37 to 0.83 ) and antiCCP-negative RA (AP $0.18,95 \%$ CI -0.72 to 1.08). The combination of the homozygous PADI4 haplotype and smoking increased the risk in patients with RA (for ero- sive RA (OR 4.22, 95\% CI 1.95 to 9.17); for non-erosive RA (OR 8.59, 95\% CI 3.27 to 22.56)) (Supplementary table S2 in Additional file 1). However, the gene-environment interaction between homozygous PADI4 haplotype and smoking was not observed in erosive RA (AP -0.16, $95 \%$ CI - 1.04 to 0.72 ) and non-erosive RA (AP 0.27, 95\% 0.43 to 0.97$)$.

\section{Discussion}

The most significant finding of this study is that PADI4 polymorphisms are associated with RA susceptibility, regardless of anti-CCP as well as erosive joint status. Moreover, significant gene-gene interactions between homozygous PADI4 GTG haplotype and $H L A-D R B 1$ SE alleles were observed for developing anti-CCP-positive and -negative RA. Interestingly, we also observed genegene interactions in patients with non-erosive and erosive RA. An additional finding is the lack of gene-environment interaction between PADI4 polymorphisms and smoking. Our findings suggest that homozygous PADI4 GTG haplotype influences RA regardless of joint destruction, and exerts more significant effects on developing RA through interaction with SE alleles.

Several studies and meta-analyses have confirmed the strong association between PADI4 and RA in Asian populations [6-9, 38, 39]. In German and French populations, a weak association between PADI4 and RA was observed $[10,11]$. However, several studies using Caucasian populations have yielded conflicting findings [12-15] and it has 
not yet been demonstrated how the PADI4 polymorphisms influence RA susceptibility. Suzuki et al. [6] proposed that a susceptible PADI4 haplotype had significantly increased mRNA stability and half-life compared with a non-susceptibility reference haplotype, and they reported that RA-risk PADI4 haplotype homozygosity was associated with the presence of anti-CCP. Later, it was shown that anti-CCP levels were significantly higher in individuals homozygous for the PADI4 risk haplotype $[6,40]$. Several investigators have speculated that certain PADI4 polymorphisms would enhance citrullination and decrease tolerance for citrullinated proteins, which could lead to the production of anti-CCP and the development of RA [6,40]. However, the inconsistent associations between PADI4 polymorphisms and the presence or levels of anti-CCP $[6,10,11,15,20]$ raised a question about this hypothesis. In this study, we demonstrated that PADI4 polymorphisms are significantly associated with anti-CCP-positive and -negative RA. Accordingly, the $P A D I 4$ gene is more likely to play an important role in another citrullination pathway than its role in anti-CCP formation.

In a recent study, B Hoppe et al. [21] performed PADI4 effects on erosive RA in investigation of 373 patients, with non-erosive patients as controls. Interestingly, they found the association of PADI4 SNP with RA was restricted to only patients with joint destruction. However, we also observed that the combination of PADI4 genes and SE alleles increased the risk of developing nonerosive RA as well, which is a result that has not been shown previously. Our results suggest that PADI4 gene is linked to the susceptibility of RA regardless of RA severity, such as erosive joint status. This discrepancy may be due to differences in sample size and the design of the study. Our findings are based on a relatively large size and case-control study, and we think that it might represent a better estimate of results from the risk factors.

Another mechanism proposed for RA association of PADI4 is that PADI4 polymorphisms may interact with an environmental factor, smoking, via citrullinated proteins, resulting in the development of RA. However, the interaction between smoking and PADI4 polymorphisms has not been confirmed, although a possible interaction between only single PADI4 SNP and smoking has been previously reported [30]. No significant interaction was observed between RA-risk PADI4 haplotype and smoking in this population of Koreans. The number of individuals in our study is fairly large, but the number of smokers with anti-CCP-negative RA is relatively small. This may make conclusions difficult, so additional largerscale studies need to be performed.

We previously reported that PADI4 SNPs and HLA$D R B 1$ SE alleles had additive effects in terms of the risk of developing RA, although no significant gene-gene inter- action was shown between PADI4 SNPs and SE alleles because of the small sample size [8]. In this large population, significant interaction was detected between PADI4 risk haplotype homozygotes and SE alleles in both antiCCP-positive and -negative RA. These results suggest that the homozygous PADI4 risk haplotype contribution to RA pathogenesis may be influenced by $H L A-D R B 1 \mathrm{SE}$ alleles. These results conflict with a recent finding of no interaction between one PADI4 SNP and SE alleles in a large UK Caucasian population [15]. The PADI4 polymorphism and SE alleles appear to vary according to ethnicity. This discrepancy between Koreans and Caucasians could be attributed to genetic heterogeneity of RA from ethnic differences. Accordingly, these conflicting results of interaction may be explained by differences in target PADI4 SNP (padi4_89, padi4_90, padi4_92 vs padi4_94) or by differences in the major RA-susceptible SE alleles (for example, "0405 vs "0401) between Korean and Caucasian populations $[41,42]$.

\section{Conclusions}

The PADI4 gene contributed significantly to the development of RA, regardless of anti-CCP or erosive joint status. Strong gene-gene interactions between homozygous PADI4 haplotype and SE alleles occur in anti-CCP-positive/negative as well as erosive/non-erosive RA. Therefore, the PADI4 gene appears to play an important pathogenic role in all subsets of RA.

\section{Additional material}

Additional file 1 Supplementary tables S1-S2. Supplementary table S1: Interaction between PAD/4 haplotypes and smoking in susceptibility to anti-CCP-positive and -negative RA. Supplementary table S2: Interaction between PAD/4 haplotypes and smoking in susceptibility to erosive and non-erosive RA.

\section{Abbreviations}

anti-CCP: anti-cyclic citrullinated peptide antibodies; AP: attributable proportions; Cl: confidence intervals; HLA: Human Leukocyte Antigen; HLA-DRB1: Human Leukocyte Antigen-DRB1; LD: linkage disequilibrium; OR: odds ratios; PAD/4: peptidyl arginine deiminase type IV gene; RA: rheumatoid arthritis; SE: shared epitope; SNP: single nucleotide polymorphism.

\section{Competing interests}

The authors declare that they have no competing interests.

\section{Authors' contributions}

Drs. Bang and Han contributed equally to this work. Drs. Bae and Kang had full access to all of the data in this study and take responsibility for the integrity of the data and the accuracy of the data analysis. Bang and Bae participated in the study design, acquisition of data, analysis and interpretation of data, statistical aspects, and drafting of the manuscript. Han and Kang contributed to data analysis and the drafting of the manuscript. Choi and Sung contributed through the assessment of clinical aspects. All authors read and approved the final manuscript.

\section{Acknowledgements}

We are grateful to many research workers for assistance with sample preparation, data collection, and technical study. Dr. Bang's work was supported by a grant from the Korea Healthcare Technology R\&D Project (A090706). Dr. Bae's 
work was supported by a grant from the Korea Healthcare Technology R\&D Project (A084794 and A010252). Dr. Kang's work was supported by a grant from the Research Program for New Drug Target Discovery (M1074800023108N4800-23110)

\section{Author Details}

'Department of Rheumatology, Hanyang University Hospital for Rheumatic Diseases, 17 Hangdang-dong Seongdong-gu, Seoul 133-792, South Korea and 2Department of Biological Sciences, Korea Advanced Institute of Science and Technology, 335 Gwahangno Yuseong-gu, Daejeon 305-701, South Korea

Received: 23 March 2010 Revised: 10 May 2010

Accepted: 10 June 2010 Published: 10 June 2010

\section{References}

1. MacGregor AJ, Snieder H, Rigby AS, Koskenvuo M, Kaprio J, Aho K, Silman AJ: Characterizing the quantitative genetic contribution to rheumatoid arthritis using data from twins. Arthritis Rheum 2000, 43:30-37.

2. Gregersen PK, Silver J, Winchester RJ: The shared epitope hypothesis. An approach to understanding the molecular genetics of susceptibility to rheumatoid arthritis. Arthritis Rheum 1987, 30:1205-1213.

3. du Montcel ST, Michou L, Petit-Teixeira E, Osorio J, Lemaire I, Lasbleiz S, Pierlot C, Quillet P, Bardin T, Prum B, Cornelis F, Clerget-Darpoux F: New classification of HLA-DRB1 alleles supports the shared epitope hypothesis of rheumatoid arthritis susceptibility. Arthritis Rheum 2005, 52:1063-1068.

4. Jawaheer D, Thomson W, MacGregor AJ, Carthy D, Davidson J, Dyer PA, Silman AJ, Ollier WE: "Homozygosity" for the HLA-DR shared epitope contributes the highest risk for rheumatoid arthritis concordance in identical twins. Arthritis Rheum 1994, 37:681-686.

5. Lin $L$, Chen Y, Xiao Z, Huang S, Yang Z: The association of HLA-DRB1 alleles with rheumatoid arthritis in the Chinese Shantou population: a follow-up study. Biochem Cell Biol 2007, 85:227-238.

6. Suzuki A, Yamada R, Chang X, Tokuhiro S, Sawada T, Suzuki M, Nagasaki M, Nakayama-Hamada M, Kawaida R, Ono M, Ohtsuki M, Furukawa H, Yoshino S, Yukioka M, Tohma S, Matsubara T, Wakitani S, Teshima R, Nishioka Y, Sekine A, lida A, Takahashi A, Tsunoda T, Nakamura Y, Yamamoto K: Functional haplotypes of PADI4, encoding citrullinating enzyme peptidylarginine deiminase 4 , are associated with rheumatoid arthritis. Nat Genet 2003, 34:395-402.

7. Iwamoto T, Ikari K, Nakamura T, Kuwahara M, Toyama Y, Tomatsu T, Momohara S, Kamatani N: Association between PADI4 and rheumatoid arthritis: a meta-analysis. Rheumatology (Oxford) 2006, 45:804-807.

8. Kang CP, Lee HS, Ju H, Cho H, Kang C, Bae SC: A functional haplotype of the PADI4 gene associated with increased rheumatoid arthritis susceptibility in Koreans. Arthritis Rheum 2006, 54:90-96.

9. Fan LY, Zong M, Lu TB, Yang L, Ding YY, Ma JW: Association of the PADI4 gene polymorphism and HLA-DRB1 shared epitope alleles with rheumatoid arthritis. Zhonghua Yi Xue Yi Chuan Xue Za Zhi 2009, 26:57-61.

10. Gandjbakhch F, Fajardy I, Ferre B, Dubucquoi S, Flipo RM, Roger N, SolauGervais E: A functional haplotype of PADI4 gene in rheumatoid arthritis: positive correlation in a French population. J Rheumatol 2009, 36:881-886

11. Hoppe B, Haupl T, Gruber R, Kiesewetter H, Burmester GR, Salama A, Dorner $\mathrm{T}$ : Detailed analysis of the variability of peptidylarginine deiminase type 4 in German patients with rheumatoid arthritis: a casecontrol study. Arthritis Res Ther 2006, 8:R34.

12. Caponi L, Petit-Teixeira E, Sebbag M, Bongiorni F, Moscato S, Pratesi F, Pierlot C, Osorio J, Chapuy-Regaud S, Guerrin M, Cornelis F, Serre G, Migliorini P: A family based study shows no association between rheumatoid arthritis and the PADI4 gene in a white French population. Ann Rheum Dis 2005, 64:587-593.

13. Barton A, Bowes J, Eyre S, Spreckley K, Hinks A, John S, Worthington J: A functional haplotype of the PADI4 gene associated with rheumatoid arthritis in a Japanese population is not associated in a United Kingdom population. Arthritis Rheum 2004, 50:1117-1121.

14. Julia A, Ballina J, Canete JD, Balsa A, Tornero-Molina J, Naranjo A, AlperiLopez M, Erra A, Pascual-Salcedo D, Barcelo P, Camps J, Marsal S: Genomewide association study of rheumatoid arthritis in the Spanish population: KLF12 as a risk locus for rheumatoid arthritis susceptibility. Arthritis Rheum 2008, 58:2275-2286.

15. Burr ML, Naseem H, Hinks A, Eyre S, Gibbons LJ, Bowes J, Wilson AG, Maxwell J, Morgan AW, Emery P, Steer S, Hocking L, Reid DM, Wordsworth P, Harrison P, Thomson W, Worthington J, BIRAC Consortium, YEAR Consortium, Barton A: PADI4 genotype is not associated with rheumatoid arthritis in a large UK Caucasian Population. Ann Rheum Dis 2010, 69:666-670.

16. Vossenaar ER, van Venrooij WJ: Citrullinated proteins: sparks that may ignite the fire in rheumatoid arthritis. Arthritis Res Ther 2004, 6:107-111.

17. van Venrooij WJ, Pruijn GJ: Citrullination: a small change for a protein with great consequences for rheumatoid arthritis. Arthritis Res 2000, 2:249-251.

18. van der Helm-van Mil AH, Huizinga TW, Schreuder GM, Breedveld FC, de Vries RR, Toes RE: An independent role of protective HLA class II alleles in rheumatoid arthritis severity and susceptibility. Arthritis Rheum 2005, 52:2637-2644.

19. Lundberg K, Nijenhuis S, Vossenaar ER, Palmblad K, van Venrooij WJ, Klareskog L, Zendman AJ, Harris HE: Citrullinated proteins have increased immunogenicity and arthritogenicity and their presence in arthritic joints correlates with disease severity. Arthritis Res Ther 2005, 7:R458-467.

20. Cha S, Choi CB, Han TU, Kang CP, Kang C, Bae SC: Association of anticyclic citrullinated peptide antibody levels with PADI4 haplotypes in early rheumatoid arthritis and with shared epitope alleles in very late rheumatoid arthritis. Arthritis Rheum 2007, 56:1454-1463.

21. Hoppe B, Haupl T, Egerer K, Gruber R, Kiesewetter H, Salama A, Burmester GR, Dorner T: Influence of peptidylarginine deiminase type 4 genotype and shared epitope on clinical characteristics and autoantibody profile of rheumatoid arthritis. Ann Rheum Dis 2009, 68:898-903.

22. Padyukov L, Silva C, Stolt P, Alfredsson L, Klareskog L: A geneenvironment interaction between smoking and shared epitope genes in HLA-DR provides a high risk of seropositive rheumatoid arthritis. Arthritis Rheum 2004, 50:3085-3092.

23. Silman AJ, Newman J, MacGregor AJ: Cigarette smoking increases the risk of rheumatoid arthritis. Results from a nationwide study of disease-discordant twins. Arthritis Rheum 1996, 39:732-735.

24. Stolt P, Bengtsson C, Nordmark B, Lindblad S, Lundberg I, Klareskog L, Alfredsson $L$ : Quantification of the influence of cigarette smoking on rheumatoid arthritis: results from a population based case-control study, using incident cases. Ann Rheum Dis 2003, 62:835-841.

25. Mattey DL, Dawes PT, Clarke S, Fisher J, Brownfield A, Thomson W, Hajeer AH, Ollier WE: Relationship among the HLA-DRB1 shared epitope, smoking, and rheumatoid factor production in rheumatoid arthritis. Arthritis Rheum 2002, 47:403-407.

26. van der Helm-van Mil AH, Huizinga TW, de Vries RR, Toes RE: Emerging patterns of risk factor make-up enable subclassification of rheumatoid arthritis. Arthritis Rheum 2007, 56:1728-1735.

27. Klareskog L, Stolt P, Lundberg K, Kall lberg H, Bengtsson C, Grunewald J, Ronnelid J, Harris HE, Ulfgren AK, Rantapaa-Dahlqvist S, Eklund A, Padyukov $L$, Alfredsson $L$ : A new model for an etiology of rheumatoid arthritis: smoking may trigger HLA-DR (shared epitope)-restricted immune reactions to autoantigens modified by citrullination. Arthritis Rheum 2006, 54:38-46.

28. Lee HS, Irigoyen P, Kern M, Lee A, Batliwalla F, Khalili H, Wolfe F, Lum RF, Massarotti E, Weisman M, Bombardier C, Karlson EW, Criswell LA, Vlietinck $\mathrm{R}$, Gregersen PK: Interaction between smoking, the shared epitope, and anti-cyclic citrullinated peptide: a mixed picture in three large North American rheumatoid arthritis cohorts. Arthritis Rheum 2007, 56:1745-1753.

29. Bang SY, Lee KH, Cho SK, Lee HS, Lee KW, Bae SC: Smoking increases rheumatoid arthritis susceptibility in individuals carrying the HLADRB1 shared epitope, regardless of rheumatoid factor or anti-cyclic citrullinated peptide antibody status. Arthritis Rheum 2010, 62:369-377.

30. Mei L, Li X, Yang K, Cui J, Fang B, Guo X, Rotter Jl: Evaluating gene $\times$ gene and gene $\times$ smoking interaction in rheumatoid arthritis using candidate genes in GAW15. BMC Proc 2007, 1(Suppl 1):S17.

31. Arnett FC, Edworthy SM, Bloch DA, McShane DJ, Fries JF, Cooper NS, Healey LA, Kaplan SR, Liang MH, Luthra HS, et al:: The American Rheumatism Association 1987 revised criteria for the classification of rheumatoid arthritis. Arthritis Rheum 1988, 31:315-324. 
32. Steinbrocker $\mathrm{O}$, Traeger $\mathrm{CH}$, Batterman $\mathrm{RC}$ : Therapeutic criteria in rheumatoid arthritis. JAm Med Assoc 1949, 140:659-662.

33. Miller SA, Dykes DD, Polesky HF: A simple salting out procedure for extracting DNA from human nucleated cells. Nucleic Acids Res 1988, 16:1215.

34. Kotsch K, Wehling J, Blasczyk R: Sequencing of HLA class II genes based on the conserved diversity of the non-coding regions: sequencing based typing of HLA-DRB genes. Tissue Antigens 1999, 53:486-497.

35. Hosmer DW, Lemeshow S: Confidence interval estimation of interaction. Epidemiology 1992, 3:452-456.

36. Andersson T, Alfredsson L, Kallberg H, Zdravkovic S, Ahlbom A: Calculating measures of biological interaction. Eur J Epidemio/ 2005, 20:575-579.

37. Stephens M, Donnelly P: A comparison of bayesian methods for haplotype reconstruction from population genotype data. Am J Hum Genet 2003, 73:1162-1169.

38. Ikari K, Kuwahara M, Nakamura T, Momohara S, Hara M, Yamanaka H, Tomatsu T, Kamatani N: Association between PADI4 and rheumatoid arthritis: a replication study. Arthritis Rheum 2005, 52:3054-3057.

39. Takata Y, Inoue H, Sato A, Tsugawa K, Miyatake K, Hamada D, Shinomiya F, Nakano S, Yasui N, Tanahashi T, Itakura M: Replication of reported genetic associations of PADI4, FCRL3, SLC22A4 and RUNX1 genes with rheumatoid arthritis: results of an independent Japanese population and evidence from meta-analysis of East Asian studies. J Hum Genet 2008, 53:163-173.

40. Kochi Y, Suzuki A, Yamada R, Yamamoto K: Genetics of rheumatoid arthritis: underlying evidence of ethnic differences. J Autoimmun 2009, 32:158-162.

41. Lee HS, Lee KW, Song GG, Kim HA, Kim SY, Bae SC: Increased susceptibility to rheumatoid arthritis in Koreans heterozygous for HLADRB1*0405 and *0901. Arthritis Rheum 2004, 50:3468-3475.

42. Barnetche T, Constantin A, Cantagrel A, Cambon-Thomsen A, Gourraud P: New classification of HLA-DRB1 alleles in rheumatoid arthritis susceptibility: a combined analysis of worldwide samples. Arthritis Res Ther 2008, 10:R26.

doi: $10.1186 /$ ar3051

Cite this article as: Bang et al., Peptidyl arginine deiminase type IV (PADI4) haplotypes interact with shared epitope regardless of anti-cyclic citrullinated peptide antibody or erosive joint status in rheumatoid arthritis: a case control study Arthritis Research \& Therapy 2010, 12:R115

Submit your next manuscript to BioMed Central and take full advantage of:

- Convenient online submission

- Thorough peer review

- No space constraints or color figure charges

- Immediate publication on acceptance

- Inclusion in PubMed, CAS, Scopus and Google Scholar

- Research which is freely available for redistribution

Submit your manuscript at www.biomedcentral.com/submit
C Biomed Central 